Gallstones

\section{Treatment options for common bile duct stones}

\section{H R Ferguson, T J Robinson}

Answers on $p 181$.

$A^{n}$ 83 year old woman presented with a two week history of right upper quadrant pain, pale stools, dark urine, and itch. In the previous five years there had been two episodes of similar symptoms, ultrasound scan showing multiple gall bladder calculi. Past history included hypertension, type 2 diabetes mellitus, and obesity.

On examination she was not clinically icteric, apyrexic, but mildly tender in the right upper quadrant. Liver enzymes were obstructive, bilirubin $31 \mu \mathrm{mol} / \mathrm{l}$ (3-20 $\mu \mathrm{mol} / \mathrm{l})$, alkaline phosphatase $842 \mathrm{U} /$ (100-280 U/1), $\gamma$-glutamyltranspeptidase $778 \mathrm{U} / \mathrm{l}(5-50 \mathrm{U} / \mathrm{l})$.

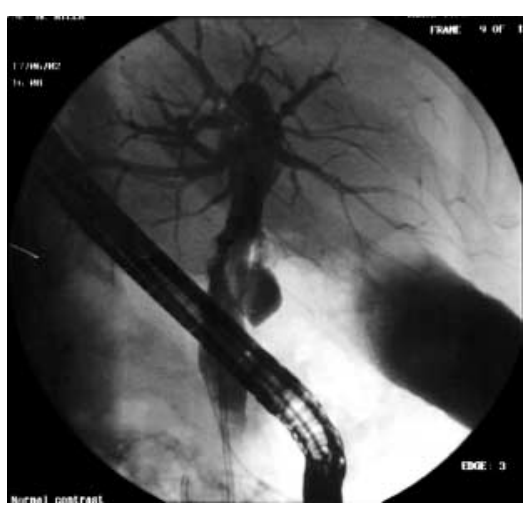

Figure 1 Post-treatment ERCP film.
On ultrasound scan there were gallbladder stones and a dilated common bile duct of $11 \mathrm{~mm}$. Endoscopic retrograde cholangiopancreatography revealed a large single calculus in the dilated common bile duct, unable to be extracted after spincterotomy.

\section{QUESTIONS}

(1) What are the treatment options for this patient?

(2) What does the post-treatment endoscopic retrograde cholangiopancreatography (ERCP) film (fig l) show?

Postgrad Med J 2003;79:178

\section{Authors' affiliations}

H R Ferguson, T J Robinson, Division of Gastroenterology, Craigavon Area Hospital, 68 Lurgan Road, Portadown, Craigavon BT63 5QQ, Northern Ireland

Correspondence to: Dr Ferguson; hrferguson@doctors.net.uk

Submitted 30 September 2002 Accepted 17 December 2002

\title{
An unusual cause of persistent vomiting
}

\section{A G Acheson, J Collyer, G A McPherson}

Answers on $p 181$.

$\Lambda^{\mathrm{n}}$ 85 year old woman presented to the outpatient department with a three month history of persistent vomiting and weight loss with associated retrosternal and epigastric discomfort. She had undergone a partial gastrectomy for benign ulcer disease 40 years previously and had an Angelchik prosthesis inserted 14 years ago for gastrooesophageal reflux. There was no other past medical history and she was currently taking no medication.

On examination she looked cachectic but no other abnormalities were detected on general or abdominal examination. Routine blood tests (full blood count, urea and electrolytes, liver function tests, and erythrocyte sedimentation rate) were all within the normal range and after this a barium meal was organised in an attempt to make a diagnosis (fig l).

\section{QUESTIONS}

(1) What abnormality is shown on the barium meal?

(2) What are the options for dealing with this complication?

(3) What other complications have been reported after insertion of this prosthesis?

\section{Authors' affiliations}

A G Acheson, J Collyer, G A McPherson, Wycombe General Hospital, Alexandra Road High Wycombe, Buckinghamshire HP1 $12 \pi$, UK

Correspondence to: Mr Acheson; austin.acheson@nottingham.ac.uk

Submitted 1 October 2002

Accepted 20 November 2002

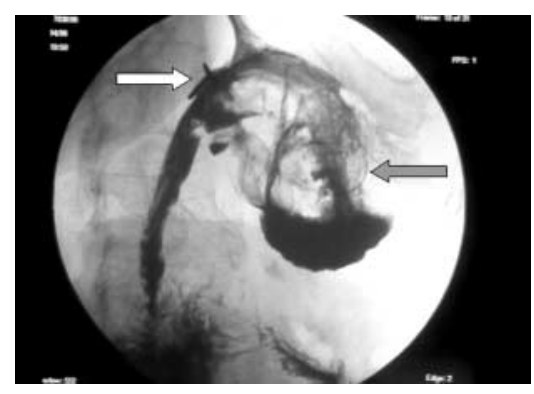

Figure 1 Barium meal. 